$\begin{array}{ll} & \text { Etnográfica } \\ \text { etnográfica } & \text { Revista do Centro em Rede de Investigação em }\end{array}$

Antropologia

vol. 24 (1) | 2020

Vol. 24 (1)

\title{
La incapacitación judicial: ¿una protección
} (in)merecida?

Legal capacity deprivation: (un)deserved protection?

\section{Juan Endara Rosales}

\section{(2) OpenEdition}

\section{Journals}

Edición electrónica

URL: https://journals.openedition.org/etnografica/8341

DOI: 10.4000/etnografica.8341

ISSN: 2182-2891

\section{Editor}

Centro em Rede de Investigação em Antropologia

\section{Edición impresa}

Fecha de publicación: 1 febrero 2020

Paginación: 165-186

ISSN: 0873-6561

\section{Referencia electrónica}

Juan Endara Rosales, «La incapacitación judicial: ¿una protección (in)merecida?», Etnográfica [En línea], vol. 24 (1) | 2020, Publicado el 25 febrero 2020, consultado el 20 enero 2022. URL: http:// journals.openedition.org/etnografica/8341 ; DOI: https://doi.org/10.4000/etnografica.8341

\section{(c) (7) \&}

Etnográfica is licensed under a Creative Commons Attribution-NonCommercial 4.0 International License. 


\section{La incapacitación judicial: ¿una protección (in)merecida?}

\section{Juan Endara Rosales}

La incapacitación judicial es una figura de protección legal ampliamente aplicada a personas que presentan discapacidades cognitivas. Se justifica en base a un criterio determinado por la consideración de la discapacidad como una enfermedad o deficiencia persistente que impide a la persona gobernarse por sí misma. Al explorar la dimensión vivida de los procesos de incapacitación, es posible atender a la elaboración de un sentimiento de injusticia que se expresa mediante un lenguaje de merecimiento respecto a aspectos que son percibidos como agravios, tanto por las personas a las que se aplican dichas medidas, como por quienes las promueven, por considerar que las medidas de protección están elaboradas con escaso o nulo conocimiento sobre las personas a las que se dirigen, están cargadas de prejuicios sobre la discapacidad y niegan derechos fundamentales. El análisis de los discursos elaborados en torno a la experiencia del proceso de incapacitación revela la utilidad de la noción de merecimiento para captar la imbricación de aspectos legales y morales en los sentimientos de injusticia.

PALABRAS CLAVE: incapacitación judicial, sentimientos de injusticia, merecimiento, antropología jurídica, estudios críticos sobre discapacidad.

Legal capacity deprivation: (un)deserved protection? - Legal capacity deprivation is a legal proceeding widely applied to protect people with cognitive disabilities. It is justified with a legal criterion that considers disability as a persistent disease or deficiency that prevents the person from governing herself. When exploring the lived dimension of the legal capacity deprivation proceedings, it is possible to notice the existence of feelings of injustice, expressed through a language of deservingness. Some aspects are perceived as grievances, both by the people whom these measures are applied to and by those who promote them. Judgers have little to no knowledge of the people these legal measures concern, the measures they impose are loaded with prejudices about disability and there is a denial of fundamental rights. The analysis of the discourses constructed around the experience of legal capacity deprivation proceedings reveals the usefulness of the notion of deservingness to capture the overlapping of legal and moral aspects in the feelings of injustice.

KEYWORDS: legal capacity deprivation, feelings of injustice, deservingness, legal anthropology, critical disability studies.

ENDARA ROSALES, Juan (juanitoendara@gmail.com) - Universitat de Barcelona, España. 


\section{LA INCAPACITACIÓN JUDICIAL EN RELACIÓN CON LOS MODELOS TEÓRICOS DE LA DISCAPACIDAD}

Para atender a la incapacitación judicial es necesario realizar un breve repaso a ciertas nociones jurídicas, así como a su relación con los modelos teóricos de la discapacidad. ${ }^{1}$ A continuación, revisaremos algunas cuestiones teóricas que nos servirán para enmarcar unos sentimientos de injusticia que surgen en torno al proceso de incapacitación judicial y que se valen de la noción de merecimiento (deservingness) para expresar unos agravios.

En Derecho, ser persona es un hecho regulado que comienza a partir del "nacimiento con vida" (Código Civil español, art. 30), el cual da lugar a lo que en sentido jurídico se conoce como "personalidad". ${ }^{2}$ Ser persona es ser portador de derechos, por ello la personalidad se refleja en la "capacidad jurídica", es decir, en la aptitud genérica para ser titular de derechos y deberes. Esta aptitud genérica y pasiva es a su vez complementada cuando, llegada la mayoría de edad, la persona adquiere "capacidad de obrar". Los derechos de los que se goza pasivamente son complementados por la capacidad para ejercer actos válidos y asumir derechos y obligaciones específicas, con eficacia y de manera activa en la esfera jurídica (Picatoste Bobillo 2006; Fernández de Buján 2011 ; Barranco, Cuenca y Ramiro 2012).

La capacidad de obrar es una presunción, es decir, un hecho que en derecho se tiene por cierto sin necesidad de que sea probado. Los únicos criterios para que esta presunción no sea "destruida" - como se dice en el lenguaje jurídico - son que la persona sea mayor de edad y que no exista una sentencia de "incapacitación judicial". ${ }^{3}$ Esta última es una figura legal que consiste

l El autor desarrolla su investigación con una ayuda para la contratación de personal investigador en formación otorgada por la Generalitat de Catalunya y el Fondo Social Europeo. Su investigación forma parte del proyecto "Concepciones Populares de la Justicia Social ante la Crisis y las Políticas de Austeridad” (CSO2015-67368-P), financiado por el Ministerio de Economía y Competitividad español y el Fondo Europeo de Desarrollo Regional (Feder), 2016-2018.

2 La fórmula "nacimiento con vida" corresponde a la modificación realizada con la Ley 20/201 1 , de 21 de julio, del Registro Civil. Antes de ella, durante 122 años la fórmula en vigor decía: "Para los efectos civiles, sólo se reputará nacido el feto que tuviere figura humana y viviere veinticuatro horas enteramente desprendido del seno materno" (art. 30, Real Decreto de 24 de julio de 1889, por el que se publica el Código Civil, Boletín Oficial del Estado, 206, de 25/07/1889 [texto consolidado], disponible en < https:/www.boe.es/buscar/act.php?id=BOE-A-1889-4763> , última consulta en febrero de 2020; el énfasis es mío).

3 Ciertas denominaciones de larga duración tienden a mantenerse años después de haberse realizado sustituciones terminológicas, incluso en los casos en que los términos han sido considerados obsoletos u ofensivos. Desde el 2009, la incapacitación judicial ha pasado a denominarse "modificación de la capacidad de obrar" (cf. Ley 1/2009, de 25 de marzo, de reforma de la Ley de 8 de junio de 1957, sobre el Registro Civil, en materia de incapacitaciones, cargos tutelares y administradores de patrimonios protegidos, y de la Ley 41/2003, de 18 de noviembre, sobre protección patrimonial de las personas con discapacidad y de modificación del Código Civil, de la Ley de Enjuiciamiento Civil de la [continua] 
en la limitación o anulación de la capacidad de actuar en derecho (obrar) de una persona. Según recoge el Código Civil español, "nadie puede ser incapacitado sino por sentencia judicial en virtud de las causas establecidas en la ley" (art. 199), siendo las causas de incapacitación "las enfermedades o deficiencias persistentes de carácter físico o psíquico que impidan a la persona gobernarse por sí misma" (art. 200). ${ }^{4}$ Así, la incapacitación judicial se aplica ampliamente a personas que presentan discapacidades cognitivas. ${ }^{5}$

La incapacitación judicial busca proteger a determinados individuos que se considera que no reúnen las facultades necesarias para autogobernarse, es decir, para tomar decisiones y realizar "actos concernientes a su propia esfera jurídica tanto en el plano estricto de la personalidad como en el plano económico o patrimonial" (Fernández de Buján 201 1: 60).

La incapacitación judicial es un proceso que se pronuncia sobre la libertad de la persona y compromete la forma de ejercicio de los derechos. Suele estar acompañada de medidas como la inhabilitación del derecho de sufragio, la negación del control sobre el propio patrimonio o la imposibilidad de establecer contratos de todo tipo. En algunos casos está asociada a prácticas como la esterilización o el ingreso involuntario en instituciones psiquiátricas. No obstante, las mismas prácticas no siempre se presentan en todos los casos, sino que su variabilidad es amplia.

El criterio bajo el cual se interpretan las causas de incapacitación tiene un marcado sesgo biomédico centrado en las enfermedades o deficiencias, la

normativa tributaria con esta finalidad, Boletín Oficial del Estado, 73, de 26/03/2009, disponible en $<$ https://www.boe.es/buscar/doc.php?id=BOE-A-2009-5028 > última consulta en febrero de 2020). El Anteproyecto de Ley por la que se reforma la legislación civil y procesal en materia de discapacidad (de 2018 , publicado en Revista de Derecho Civil, 5 (3): 247-310, disponible en < http://nreg.es/ojs/index. $\mathrm{php} / \mathrm{RDC} /$ article/view/375 > , última consulta en febrero de 2020) propone sustituir esta denominación por "procedimiento de provisión de apoyos". En el argot jurídico, la incapacitación judicial también es conocida como "muerte civil". En estas páginas utilizo la denominación "incapacitación judicial", puesto que es la que emerge en mayor medida en los contextos etnográficos.

4 Desde su promulgación en 1889, el Código Civil español ha experimentado algunas modificaciones parciales. En el caso que nos ocupa, antes de la modificación realizada con la Ley 13/1983, de 24 de octubre, de Reforma del Código Civil en materia de tutela (publicada en Boletín Oficial del Estado, 256, de 26/10/1983, disponible en < https://www.boe.es/buscar/doc.php?id=BOE-A-1983-28123>, última consulta en febrero de 2020), los artículos en cuestión se referían a "la tutela de los incapaces de gobernarse por sí mismos", especificando que estaban sujetos a tutela "los menores de edad no emancipados legalmente; los locos o dementes, aunque tengan intervalos lúcidos, y los sordomudos que no sepan leer y escribir; los que por sentencia firme hubiesen sido declarados pródigos; y los que estuviesen sufriendo la pena de interdicción civil" (Real Decreto de 24 de julio de 1889, arts. 199 y 200). Cabe notar que estos textos legislativos estuvieron en vigor durante 94 años.

5 Este término no se corresponde con una categoría diagnóstica concreta, sino que con él se busca captar la diversidad de situaciones que conforman el grupo que se corresponde con el texto legal: personas que presentan demencia, Alzheimer, esquizofrenia, trastornos de la personalidad, trisomía 21 (síndrome de Down), discapacidad intelectual (retraso mental), trastornos del espectro autista, entre otros diagnósticos. 
afectación al autogobierno que estas causan y la persistencia en el tiempo. Este sesgo se corresponde con lo que en los estudios críticos de la discapacidad (critical disability studies) se conoce como el modelo médico-rehabilitador. ${ }^{6}$ Este modelo se refiere al proceso mediante el cual las personas son consideradas inherentemente discapacitadas de acuerdo con definiciones y categorizaciones que interpretan la discapacidad solamente como una enfermedad, de manera que quienes la "padecen" o "sufren" requieren de atención médica permanente para ser "curados" o "rehabilitados" y así poder participar en la sociedad. Cuando la rehabilitación no es posible, se despliega el "cuidado" o "custodia" en instituciones especializadas. Desde este modelo se tiene un enfoque individualizador y la interpretación de la discapacidad se reduce al sustrato fisiológico que la origina, es decir, la deficiencia. De aquí que entre las prácticas y representaciones de este modelo consten la medicalización, el paternalismo, la institucionalización, la reificación y la normalización, entre otras (Palacios 2008; Toboso y Guzmán 2009; Rodríguez y Cano 2015).

En contraposición al modelo médico-rehabilitador, desde los estudios críticos de la discapacidad se ha teorizado el denominado modelo social, el cual sostiene que las personas que presentan deficiencias resultan discapacitadas por un entorno que no tiene en cuenta sus particularidades y requerimientos, por lo que se las excluye de la participación en la sociedad convencional. Esta situación discapacitante es, por lo tanto, una fuente de opresión social (UPIAS 1976: 14). Desde esta perspectiva, es supuesto fundamental que la discapacidad tiene un origen social, por lo que, si se eliminan las barreras que evitan la participación, las personas pueden aportar a sus comunidades (Palacios 2008: 103-104).

El modelo social ha sido plasmado en el ordenamiento jurídico español a través de la ratificación de la Convención de las Naciones Unidas sobre los Derechos de las Personas con Discapacidad. ${ }^{7}$ Este convenio reconoce en su preámbulo que la discapacidad "es un concepto que evoluciona y que resulta de la interacción entre las personas con deficiencias y las barreras debidas a la actitud y al entorno que evitan su participación plena y efectiva en la sociedad, en igualdad de condiciones con las demás" (ONU 2006).

El artículo 12 de la Convención se expresa sobre el igual reconocimiento como persona ante la ley y estipula la obligación de los Estados partes a reconocer la personalidad jurídica de las personas con discapacidad en todas partes,

6 La discapacidad se diagnostica oficialmente por profesionales de la medicina y, a efectos de la incapacitación judicial, quienes realizan las labores de medicina forense y quienes valoran la afectación del autogobierno (incluido el considerado necesario para ejercer el derecho de sufragio).

7 En vigor desde el 9 de abril de 2008 en España ( $c f$. "Instrumento de ratificación de la Convención sobre los Derechos de las Personas con Discapacidad, hecho en Nueva York el 13 de diciembre de 2006", Boletín Oficial del Estado, 96, de 21/04/2008, disponible en < http://www.boe.es/buscar/doc. php?id=BOE-A-2008-6963 > , última consulta en febrero de 2020). 
a reconocer su capacidad jurídica en igualdad de condiciones con las demás en todos los aspectos de la vida, la obligación de adoptar medidas pertinentes para proporcionar acceso a los apoyos que se puedan necesitar en el ejercicio de la capacidad jurídica, la obligación de establecer salvaguardias adecuadas y efectivas para impedir abusos y asegurar que todas estas medidas respeten los derechos, la voluntad y las preferencias de la persona, que no haya conflicto de intereses ni influencia indebida, que sean proporcionales y adaptadas a las circunstancias personales (ONU 2006). El igual reconocimiento como persona ante la ley está vinculado con otros derechos humanos establecidos en la Convención. ${ }^{8}$

La práctica de la incapacitación no sólo muestra una interpretación de la discapacidad que entra en conflicto con la que recoge la Convención, sino que además corresponde a un paradigma sustitutivo de la voluntad y preferencias de la persona. Como señala el Comité sobre los Derechos de las Personas con Discapacidad (CRPD) en la Observación General a propósito del artículo 12 de la Convención, "no se ha comprendido en general que el modelo de la discapacidad basado en los derechos humanos implica pasar del paradigma de la adopción de decisiones sustitutiva a otro que se base en el apoyo para tomarlas" (CRPD 2014: 1). La práctica histórica de negar la capacidad jurídica "en virtud de regímenes basados en la sustitución en la adopción de decisiones como la legislación sobre la salud mental, la tutela y la custodia" es claramente percibida como una práctica discriminatoria, por lo que el Comité no duda en señalar que debe ser abolida (CRPD 2014: 2).

\section{SENTIMIENTOS DE INJUSTICIA Y RECLAMOS DE (IN)MERECIMIENTO}

Desde la perspectiva del modelo social, la sistemática asignación de un estatus inferior es una fuente de opresión hacia las personas con discapacidad. La conceptualización en términos de opresión implica que se trata de una inferiorización que tiene que ver con el hecho de presentar una deficiencia, que existe una relación dialéctica entre las desventajas asociadas a tal inferiorización, que las ideologías que justifican y perpetúan estas situaciones no son ni naturales ni inevitables y que en última instancia alguien se beneficia del mantenimiento de estas situaciones (Abberley 1987: 7).

8 Sin igual reconocimiento de la personalidad jurídica se ven afectados el derecho a la igualdad y la no discriminación (arts. 5 y 6), el derecho a la accesibilidad (art. 9), el derecho al acceso a la justicia (art. 13), el derecho a no ser internado contra la propia voluntad en una institución de salud mental y a no ser obligado a someterse a un tratamiento de salud mental (art. 14), el derecho al respeto de la integridad física y mental (art. 17), el derecho a la libertad de desplazamiento y a la nacionalidad (art. 18), el derecho a elegir dónde y con quién vivir (art. 19), el derecho a la libertad de expresión (art. 21 ), el derecho a la privacidad (art. 22), el derecho a casarse y fundar una familia (art. 23), el derecho a dar el consentimiento propio para recibir un tratamiento médico (art. 25), el derecho a participar en la vida pública y política (art. 9) (CRPD 2014: 9-14). 
La opresión y la dominación han sido señaladas como condiciones que definen la injusticia. Siguiendo la conceptualización ofrecida por Iris Marion Young, la opresión consiste en procesos institucionales sistemáticos que impiden a ciertas personas aprender y utilizar habilidades satisfactorias y expansivas en medios socialmente reconocidos y que anulan su capacidad para interactuar y comunicarse con otras personas, expresar sus sentimientos y perspectiva sobre la vida social, en contextos donde sean escuchadas. A su vez, la dominación está caracterizada por la presencia de condiciones institucionales que impiden a ciertas personas participar en la determinación de sus acciones o de las condiciones en que las realizan; estas condiciones permiten que sean otras personas o grupos las que pueden determinar sin relación de reciprocidad las condiciones de sus acciones, de manera directa o en base a las consecuencias estructurales de sus acciones (Young 2000: 68).

Para las personas con discapacidad, las condiciones de opresión y dominación se traducen en dos poderosos sentimientos de injusticia que se yuxtaponen: la percepción de ser tratado como alguien inferior (en sentido moral, social, político) en base a unas características arbitrarias; y la creación, perpetuación o el fallo en la corrección de las desigualdades (en ingresos, salud, bienestar, derechos, entre varias otras) sobre la base de factores morales irrelevantes (Putnam et al. 2019).

Desde la teoría de la justicia, se han conceptualizado dos dimensiones elementales en las que se originan las injusticias. Por una parte, las injusticias que tienen que ver con la redistribución (injusticias socioeconómicas); y, por otra parte, las injusticias que tienen que ver con el reconocimiento (injusticias culturales o simbólicas). Sin embargo, cabe tener en cuenta que se trata de una distinción puramente analítica, ya que en la práctica ambas formas de injusticia se entrecruzan, reforzándose dialécticamente y dando lugar a un círculo vicioso de subordinación cultural y económica (Fraser 2000: 129-131).

Esta conceptualización ha sido criticada por partir de una oposición entre economía política (dimensiones materiales) y cultura (dimensiones simbólicas). En opinión de Young (1997: 154-156), sería más apropiado reconectar los problemas a los que da lugar el mal reconocimiento con las consecuencias que tiene en la organización material del trabajo, el acceso a los recursos y el poder de decisión, en lugar de solidificar una dicotomía entre reconocimiento y redistribución.

La noción de merecimiento y el lenguaje que se despliega en torno a ella se plantea como una interesante posibilidad analítica para dar cuenta de los distintos sentimientos de injusticia más allá de lógicas dicotómicas. Originadas alrededor del siglo XIV ${ }^{9}$ las ideas sobre merecimiento han sido utilizadas 
con frecuencia para distinguir entre "verdaderos y falsos pobres", aquellos que merecen algún tipo de alivio - sea este económico o de otro tipo - y aquellos que no, en base a valoraciones morales que casi siempre han sobrepasado a las distinciones pragmáticas cuando se han ensayado clasificaciones entre merecedores e inmerecedores (Katz 1989: 10). La noción de merecimiento también refiere a la justicia retributiva, en donde se utiliza en relación con la pena impuesta a quien comete un delito (Walen 2016). La expresión (dar o recibir) "su merecido" obedece a este uso de la noción y, como recoge el Diccionario de la Lengua Española, el merecido es el "castigo de que se juzga digno a alguien". ${ }^{10}$

Ser considerado merecedor es ser considerado miembro de una categoría moral, con las consecuencias que ello conlleva. En el caso de la distinción entre pobres merecedores e inmerecedores con relación al desempleo, ser ubicado en un lado de la valoración moral implica ser considerado como independiente, responsable, capaz, autónomo; ser ubicado en el otro lado de la valoración moral implica ser considerado como irresponsable, dependiente, incapaz (Howe 1990: 1). En ambos lados de la valoración existe la configuración de un estatus moral. Al respecto, Katz (1989: 22) señala que los científicos sociales liberales compartían unos supuestos fundamentales a propósito de los pobres, notablemente la imagen de quienes dependen de recursos públicos como "pasivos, carentes de voluntad y capacidad organizacional para atacar las fuentes de su explotación y degradación”. En esta misma línea, refiere las descripciones y teorizaciones realizadas por el politólogo Edward C. Banfield sobre la llamada lower-class, en las que sus integrantes emergen como "menos que completamente humanos" (Katz 1989: 32).

Un reclamo de merecimiento es un reclamo en el sentido de que alguien merece algo de alguien sobre alguna base. Estos reclamos no siempre dependen de la existencia previa de leyes, contratos, instituciones legales o sociales. Por otra parte, un reclamo de derecho es un reclamo en el sentido de que alguien tiene derecho a algo de alguien sobre alguna base. Tener derecho esencialmente refiere a una relación que involucra la existencia de instituciones legales o sociales: una persona puede tener derecho a algo en virtud de reglas que existen en su sociedad, a pesar de no merecerlo. El merecimiento tiene una base moral, más ligada a la conducta, mientras que el derecho necesariamente tiene una base legal, empírica, sociológica (Feldman y Skow 2016). Pese a

Pobres y Reducción de los Fingidos. Estas distinciones se plasmaron, por ejemplo, en la Ley de Beneficencia de 1849, en la disposición de inadmisión de "pobres o mendigos válidos" a los establecimientos de beneficencia ( $c f$. Ley de Beneficencia de 20 de junio de 1849, en Gaceta de Madrid, 5398, de 24/06/1849, disponible en < https://www.boe.es/datos/pdfs/BOE/1849/5398/A00001-00002.pdf > última consulta en febrero de 2020).

10 Cf. "merecido", en Diccionario de la Lengua Española, Real Academia Española, 2017, disponible en $<$ https://dle.rae.es/merecido? $\mathrm{m}=$ form $>$ (última consulta en febrero de 2020). 
estas aclaraciones formales, es importante atender al uso lego de la noción de merecimiento - el que ocurre en el habla cotidiana - ya que es posible que tales distinciones no aparezcan claramente formuladas, sino que, al contrario, en la expresión de los sentimientos de injusticia y los reclamos de justicia se tienda a articular elementos de las esferas de la moral y del derecho.

Si bien la literatura sobre la noción de merecimiento parece haberse concentrado en la imbricación de aspectos legales y morales en torno a la asignación de recursos de tipo económico, ${ }^{11}$ también existen indagaciones que han prestado atención a dicha imbricación en la asignación de recursos de tipo jurídico. ${ }^{12}$ Por tanto, se intuye la utilidad de la noción para abordar reclamos de asignaciones en las que se articulan aspectos materiales e inmateriales. Adicionalmente, esta utilidad también se aprecia en las posibilidades analíticas que ofrece la noción para atender a las justificaciones esgrimidas por parte de quienes administran recursos, sea para denegar o aceptar los reclamos, se basen estos en apelaciones al derecho formal o a una determinada moral. El lenguaje del merecimiento permite rastrear la dimensión moral de los conflictos, lo cual, a su vez, lleva a visibilizar las ideologías que operan en las situaciones percibidas como injustas.

En lo que sigue, atenderemos al uso de la noción de merecimiento en la asignación (o negación) de recursos inmateriales como el estatus civil y las reacciones a las que esto da lugar. Concretamente, nos fijaremos en la dimensión vivida de la incapacitación judicial, puesto que en ella se aprecia la elaboración de un sentimiento de injusticia que se expresa mediante un lenguaje que recurre a la noción de merecimiento para señalar distintos aspectos que son percibidos como agravios, tanto por las personas a las que se incapacita, como por quienes promueven la incapacitación. Estos agravios tienen que ver con decisiones judiciales que se considera que están tomadas con escaso o nulo conocimiento de las personas a las que se aplican, que están cargadas de prejuicios sobre la discapacidad y que, en definitiva, niegan derechos fundamentales.

\section{EL LENGUAJE DEL MERECIMIENTO EN LA INCAPACITACIÓN}

Si bien la incapacitación judicial es una práctica bastante extendida entre personas a las que se ha diagnosticado discapacidad intelectual, esto no quiere decir que se lleve a cabo en todos los casos. ${ }^{13}$ Cuando se hace, generalmente ocurre en

11 Como los distintos tipos de alivio, ayudas o prestaciones económicas a "pobres merecedores". $\mathrm{Al}$ respecto, ver Howe (1990) y Katz (1989).

12 Por ejemplo, la asignación de un estatus legal a migrantes en función de su comportamiento y desempeño cívico. Al respecto, ver Chauvin, Garcés-Mascareñas y Kraler (2013); Chauvin y Garcés-Mascareñas (2014).

13 Los datos etnográficos que utilizo forman parte de una investigación en curso que vengo realizando desde junio de 2015. Valiéndome de los relatos sobre los procesos de incapacitación, el estudio de las sentencias y documentación judicial relevante, entrevistas a abogados y el [continua] 
torno a la obtención de la mayoría de edad de la persona a la que se incapacita, idealmente antes de que ello ocurra, aunque no siempre es así. El proceso suele ser iniciado por los progenitores de la persona a la que se quiere incapacitar. $\mathrm{Al}$ menos uno de ellos "denuncia" a su hijo o hija como presunta incapaz, a través de una demanda, redactada por un profesional del derecho. El proceso requerirá que se citen a declarar a testigos, que quien instruye el caso se entreviste con la persona a la que se demanda y que se realicen determinadas pruebas médico-forenses para conocer la afectación de la deficiencia al autogobierno.

La incapacitación no es un proceso gratuito, sino que tiene costes económicos y temporales. En cuanto a los costes económicos, no existe un precio estandarizado, sino que estos oscilan entre los 400 y los 1200 euros, cuando se trata de un proceso en el que no hay inconformidades con la sentencia judicial. ${ }^{14}$ Esta oscilación depende de si el proceso se realiza a través de un despacho de abogados o si se realiza a través de alguna entidad tutelar del sector formal de la discapacidad que ofrezca estos servicios. ${ }^{15}$ Generalmente, estos costes los asume la familia. En cuanto a los costes temporales, el proceso suele tomar aproximadamente un año desde que se realiza la demanda y hasta que se emite la sentencia. Sin embargo, al considerar la cuestión desde una perspectiva más amplia, el tiempo que requiere es más dilatado: pueden transcurrir unos años desde las primeras "recomendaciones" que se hacen a la familia, hasta que por fin se deciden a realizar la demanda. ${ }^{16}$ Estos tiempos pueden ampliarse aún más si existen inconformidades con las sentencias y se realizan recursos de apelación. En tal caso, los costes del proceso aumentan. Todo depende de hasta qué instancia se eleve el caso. ${ }^{17}$

No se puede afirmar que la incapacitación de lugar a inconformidades en todos los casos. Después de todo, la intencionalidad de protección - una intención moral - es la que motiva a iniciar un proceso de incapacitación. Sin embargo, en los casos en que surgen inconformidades, es posible encontrar

acompañamiento durante uno de los procesos, en una primera fase profundicé en tres casos en los que las medidas adoptadas en la sentencia fueron consideradas injustas. Para ampliar al respecto, ver Endara Rosales (2018).

14 En general se trata de honorarios profesionales de servicios de abogacía y procuraduría.

15 Desde el año 1983, determinadas personas jurídicas pueden ejercer funciones tutelares asignadas por sentencia judicial (Ley 13/1983, de 24 de octubre), de allí que algunas entidades tutelares ofrezcan asesoría y servicios legales.

16 Una perspectiva más amplia quiere decir que no se remita solamente a la actuación jurisdiccional (proceso, juicio de incapacitación) ni a las escasas y artificiales interacciones en tribunales (procedimiento, actos procesales como la entrevista con el juez, la evaluación médico-forense, las audiencias a familiares y testigos).

17 La incapacitación corresponde a la jurisdicción de primera instancia. Siguiendo la jerarquía de los tribunales, los recursos de apelación a las decisiones de esta jurisdicción corresponden a las Audiencias Provinciales; a su vez, los recursos a las sentencias de estas van a los Tribunales Superiores de Justicia; y los recursos a las decisiones de estos tribunales al Tribunal Supremo o al Tribunal Constitucional, cuando las alegaciones se refieren a las competencias de este último. 
la expresión de ciertos sentimientos de injusticia frente a ciertos agravios que, junto a otras regularidades en la manera de juzgar, sugieren la existencia de una tipología específica de caso.

En los casos abordados en esta investigación, los sentimientos de injusticia se debieron a agravios relacionados con la falta de accesibilidad del proceso, la representación estereotipada de la discapacidad que manejan los juzgadores, la realización de pruebas médico-forenses que enfatizan la deficiencia, el escaso o nulo conocimiento de la persona que permite la alta burocratización del proceso, la asignación de medidas judiciales distintas a las solicitadas y la privación del derecho de sufragio. Pese a que estos agravios están interrelacionados, no siempre emergen en todos los relatos ni con igual intensidad. La excepción, sin embargo, es la privación del derecho de sufragio, cuestión que es tenida como más lesiva y que genera un sentimiento de injusticia mayor, el cual a veces da lugar a reclamos que se expresan mediante acciones a través de vías formales - recursos de apelación de las sentencias dictadas para recuperar el derecho de sufragio -, así como acciones que se expresan por vías informales, es decir, acciones que no se despliegan como un proceso judicial y que se manifiestan mediante la queja, la reivindicación frente a actores considerados relevantes, la militancia y la crítica. $^{18}$

Centrándonos en el agravio que implica la privación del derecho de sufragio, resulta interesante considerar el lenguaje utilizado para expresar los sentimientos de injusticia, por cuanto en él es posible percibir reclamos de merecimiento, conflictos entre valoraciones morales y apelaciones a derechos formales. Tomemos por ejemplo el caso de María, relatado por su madre:

"Nosotros habíamos pedido expresamente mantener el derecho a votar porque considerábamos que Maria podía ejercer, porque bueno, desde que cumplió 18 años había votado en las elecciones que tocaba con toda la ilusión del mundo, porque considerábamos que estaba suficientemente 'capacitada' [hace el gesto de comillas con los dedos] para saber a quién tenía que votar y a quién no, que nunca se le había dicho que votase a uno u otro, sino que había sido ella quien había decidido" [Núria, comunicación personal].

En la sentencia, nada de esto queda recogido, sino que, por el contrario, lo que prima es una valoración en clave médica de las capacidades. Se aprecia una representación de la discapacidad como reducción a la deficiencia, lo cual

18 Si bien las acciones formales resultan más visibles desde una perspectiva judicial, puesto que llevan a cambiar la sentencia percibida como injusta, sería un error considerarlas como más importantes que las acciones informales: factores como la alta burocratización de los procesos judiciales, los costes (económicos, temporales y emocionales), el temor al fracaso de la acción formal y la eventual penalización (real o percibida) que pueda comportar, explican que no todas las quejas se traduzcan en acciones formales. 
permite al juzgador considerar que la persona merece ser declarada incapaz, de acuerdo con los criterios que exige el texto legal (presentar deficiencias irreversibles que afecten el autogobierno). Lo que queda recogido en el apartado dedicado a los fundamentos de derecho es ilustrativo:

"Como resulta de las limitaciones concretas que describe el informe forense en base a las cuales concluye que la incapacitación debe afectar a ambas esferas, personal y patrimonial, coincidiendo con lo apreciado en la exploración practicada directamente por mi $[s i c]$ y de acuerdo con la posición del Ministerio Fiscal, la demandada no tiene capacidad para el razonamiento formal, ni capacidad de abstracción y elaboración conceptual sobre bases inmateriales e ideas complejas. Puede solo [sic], y lo hace, desarrollar tareas simples, mecánicas, en las que ejecuta las pautas recibidas sin tener que hacer valoraciones de dicho tipo ni enfrentarse a situaciones no previstas, ante las cuales su grado de inteligencia muy inferior al normal le impide operar reflexivamente y por si $[$ sic $]$. Esta insuficiencia intelectiva hace que cuando ha de enfrentarse a relaciones causa-efecto que no sean directamente perceptibles por los sentidos al no ser mecánicas o materiales, sino abstractas y formales, no pueda comprender suficientemente las consecuencias, ni prever representativamente los efectos, ni, por tanto, tomar decisiones adecuadas. Examinemos lo respondido en la exploración y observaremos que la demandada repite y emplea términos que no comprende y no puede definir. Confundió propiedad con alquiler de una vivienda, conceptos que están a la orden del día; demostró que no capta la idea de peso y ni la distingue de la idea de volumen, que son conceptos sensibles a los que se enfrenta en todo momento en sus relaciones con el mundo exterior; no es capaz de utilizar los transportes públicos por si, salvo algún trayecto que le ha debido ser explicado previamente; no tiene una idea del valor del dinero, ni capacidad de cálculo suficiente para el control de los pagos, ni puede planificar en materia económica porque carece de inteligencia para ijar [sic] prioridades. Todo ello configura una insuficiencia generalizada que no puede entenderse afecte a solo [sic] algunos aspectos aislando otros en los que la demandada sea capaz. Lo que ocurre es que a algunas cuestiones se les atribuye por la demandante una menor importancia, probablemente partiendo del patrón valorativo predominante en una sociedad de hegemonía mercantil y dineraria, como es la actual, en la que lo fundamental es el dinero y la economía que gira en torno al mismo y se tiende a pensar que a salvo este aspecto lo restante es de menor trascendencia" [sentencia de incapacitación, fundamentos de derecho, motivo segundo].

Esta representación, que desmerece las capacidades de la persona demandada y enfatiza las deficiencias, es utilizada por el juzgador como argumento 
para declarar la incapacidad. A su vez, la enlaza con su propia concepción sobre lo que es el sufragio, para argumentar que la persona demandada no merece conservar el derecho de sufragio, contrariamente a lo que habían solicitado sus progenitores en la demanda de incapacitación. En opinión del juzgador:

"El voto como mecanismo individual de participación en las elecciones, aún [sic] cuando no esté configurado más que como manifestación de voluntad, sin que exija la expresión de motivación ni justificación alguna, es, por su propia naturaleza derivada de los principios de pluralismo político y libertad, un acto personalísimo, voluntario, libre y selectivo. Estas características hacen que no pueda ejercerse por personas que tienen disminuidas sus facultades cognitivas o volitivas, o limitada la capacidad de comprensión y decisión autónoma en grado que les inhabilita para optar por si [sic] entre las distintas opciones electorales, acomodando su decisión a sus propias expectativas sociales" [sentencia de incapacitación, fundamentos de derecho, motivo cuarto].

Esta representación sobre el derecho de sufragio parte de una idealización que a la vez erige una clasificación en arreglo a determinadas facultades esenciales: carecer de ellas justifica la negación del derecho y comporta para la persona demandada volverse inmerecedora de la participación en la vida política, a la cual hasta entonces tenía derecho. ${ }^{19}$ Desde la perspectiva del juzgador no toda voluntad merece ser tenida como tal, sino que los límites de pertenencia a la comunidad política estarían rigurosamente trazados por la posesión de unas facultades coincidentes con los valores liberales. ${ }^{20}$

La negación del derecho de sufragio genera dolor. Se sabe de antemano que es un posible resultado del proceso de incapacitación, de allí que se utilicen tácticas para sortear la denegación derivada de la exploración médico-forense y la entrevista judicial, las cuales incluyen preguntas sobre los conocimientos de la persona para participar en la vida política. El error ante alguna de estas preguntas puede comportar la negación del derecho. Esta situación angustia de manera considerable tanto a las personas demandadas como a las que promueven sus procesos, por eso es habitual que se preparen y repasen sus conocimientos sobre la organización política del Estado. ${ }^{21}$

Esta especie de prueba de conocimientos para participar en la vida política no está estandarizada ni sistematizada; sin embargo, parece ser muy fiable

19 La paradoja es máxima por cuanto la misma gravedad con que se considera la "incapacidad" para el sufragio futuro está totalmente ausente respecto al sufragio pasado.

20 Para una crítica de la teorización liberal del contrato social, ver Simplican (2015).

21 Estas "pruebas" pueden incluir conocimientos generales (saber el nombre del rey, del presidente o de los principales partidos políticos) y otros más específicos (la conformación de la mesa del Senado, el nombre de quien preside el congreso, la ideología de los partidos políticos). 
para determinar que la persona demandada no merece conservar el derecho de sufragio. En opinión de un juez con experiencia en procesos de incapacitación:

"La prueba judicial no es médica, pero lo parece. Se consideran aspectos como si la persona sabe contar, si sabe los precios de algunos productos, sus relaciones familiares, si sabe quién es el presidente del gobierno - si la persona [a la que se le pregunta] responde 'Mariano Rajoy' o 'Felipe González' [risas], o si se le pregunta quién es el rey de España y la persona responde 'Juan Carlos' o 'Alfonso XII' [risas]” [notas de campo, enero 2018].22

Cabe considerar que la representación estereotipada - representar a las personas demandadas como desubicadas en el tiempo - conforma otro de los sentimientos de injusticia y guarda una profunda relación con el sesgo médico-rehabilitador desde el que se interpreta la discapacidad en los procesos de incapacitación. Esto es constatable en la manera en que se realizan algunas exploraciones forenses y entrevistas judiciales, las cuales parecen apuntar más a dejar patente la deficiencia, considerando solamente las carencias de la persona. Tal como queda plasmado en las sentencias de incapacitación:

"Una persona con un retraso mental moderado, que la se sitúa [sic] dos grados por debajo de lo que en los tests [sic] aplicables para la graduación del coeficiente intelectivo se califica de inteligencia límite, susceptible ya de dar lugar a la incapacitación, y tres grados por debajo del límite mínimo normal, no puede captar las situaciones que condicionan la eficacia de su voto en orden a la efectividad de sus intereses de acuerdo con su posición en la sociedad, porque no puede comprender cual es tal posición, ni qué opción conviene a la misma. Todo esto supone el manejo de ideas y conceptos que no capta ni puede comprender. Las respuestas dadas al ser tratado el tema en la entrevista no dejan lugar a duda sobre ello" [sentencia de incapacitación de Karla, fundamentos de derecho, motivo cuarto].

"Una persona con un retraso mental ligero, que, no incurramos en confusión por el término "ligero", la se sitúa $[s i c]$ un grado por debajo de lo que se califica de inteligencia límite, susceptible ya de dar lugar a la incapacitación, y dos grados por debajo del límite intelectivo mínimo normal, no puede captar las situaciones que condicionan la eficacia de su voto en orden

22 Esta declaración ocurrió en una formación que recibían operadores jurídicos a propósito del proceso de incapacitación. Generó risas entre los asistentes por la exageración de la respuesta errónea, pasando por alto el error en que caía quien la realizaba: entre los reinados de ambos monarcas median más de 100 años (Juan Carlos I, rey entre 1975 y 2014; Alfonso XII, rey entre 1874 y 1885) y en el momento de la broma hacía más de tres años de la abdicación del primero. 
a la efectividad de sus intereses de acuerdo con su posición en la sociedad, porque no puede comprender cual es tal posición, ni qué opción conviene a la misma. Todo esto supone el manejo de ideas y conceptos que no capta ni puede comprender. Las respuestas dadas al ser tratado el tema en la entrevista no dejan lugar a duda sobre ello, pero es que además estamos ante una persona con una edad mental de siete $\mathrm{u}$ ocho años, según estimación de uno de los deponentes en juicio, edad que se corresponde con el coeficiente intelectual, lo que permite plantear, ante la insistente petición de la demandante, la siguiente pregunta: Cómo se explicaría jurídicamente que la aquí demandada pudiera votar, cuando la Ley no lo permite hasta que se ha alcanzado la madurez correspondiente a la edad de dieciocho años" [sentencia de incapacitación de Maria, fundamentos de derecho, motivo cuarto].

No se trata simplemente de la objetivación de la deficiencia, sino que estas representaciones son necesarias para constituir las medidas de protección según exige el texto legal. Pero como se trata de representaciones devaluadas, ocurre que junto con las medidas de protección se crea un estatus jurídico percibido como inferior: el sesgo médico-rehabilitador con que se interpreta la deficiencia no delimita solamente lo que la persona puede hacer, sino que le asigna una especie de destino social caracterizado por la negación de capacidades, habilidades y, en consecuencia, derechos. Esto se vuelve evidente al considerar las sentencias, en las que eventualmente se puede apreciar que a la enunciación del diagnóstico le sigue la fijación de un pronóstico.

Caso de Maria:

Diagnosis: "[La demandada] padece un retraso mental ligero, patología y deficiencia de carácter permanente e irreversible, que la incapacita para el autogobierno en todos los ámbitos y aspectos de la vida, sin perjuicio de las actividades y cometidos que, bajo el control permanente de quien deba suplir su falta de capacidad, se le pueda ir permitiendo puntualmente que desempeñe" [sentencia de incapacitación, fundamentos de derecho, motivo segundo].

Prognosis: "La demandada no tiene capacidad para el razonamiento formal, ni capacidad de abstracción y elaboración conceptual sobre bases inmateriales e ideas complejas. Puede desarrollar tareas simples, mecánicas, en las que ejecuta las pautas recibidas sin tener que hacer valoraciones de dicho tipo ni enfrentarse a situaciones no previstas, ante las cuales el grado su inteligencia, muy inferior al normal, le impide operar reflexivamente y por si $[$ sic]" [sentencia de incapacitación, fundamentos de derecho, motivo segundo]. 
Caso de Diana:

Diagnosis: "[La demandada] padece trastorno de la personalidad esquizoide, de la personalidad dependiente de la personalidad por autodesvaloración [sic] y de la personalidad Borderline [sic] lo que se traduce en grave dificultad para el contacto con la realidad con un grave deterioro de su capacidad laboral afectiva emocional y social [sic], lo cual no es incompatible con una limitada capacidad de gobierno de su esfera personal, dado que puede realizar por sí misma todos los actos relativos a su aseo personal vestido alimentación [sic], pero siempre que no esté afecta [sic] por una crisis invalidante en cuyo caso parece sumirse en una pasividad y astenia absoluta que la inhabilita para regir su persona y bienes con carácter total y absoluto" [sentencia de incapacitación, fundamentos de derecho, motivo segundo].

Prognosis: "La demandada no es capaz de regirse por sí misma, de administrar sus bienes, y no posee juicio o criterio suficiente para discernir en cualquier acto o situación cotidiana así como es inhábil para responsabilizarse de su propia vida. Esto le priva de capacidad de autodeterminación e independencia para todo tipo de actividades de naturaleza patrimonial, si bien en el aspecto personal desarrolla con autonomía aunque con necesidad de supervisión por terceras personas simples actividades manuales y domésticas" [sentencia de incapacitación, fundamentos de derecho, motivo segundo].

La diagnosis es determinante, de allí que deba presentarse de manera sólida, en los términos médico-rehabilitadores que requiere el texto legal, para justificar la asignación de las medidas que el juzgador considera merecidas (incapacitación plena y privación del derecho de sufragio). A su vez, lo que hemos llamado prognosis muestra como estas representaciones dan lugar a una ordenación jerárquica y a una inferiorización moral: si la ausencia de deficiencias se corresponde con la plena capacidad para el ejercicio de derechos, la presencia de ciertas deficiencias ${ }^{23}$ vuelve a las personas inmerecedoras de participar en el contrato, por tanto, se las considera merecedoras de la tutela (Alvarez-Uría 1983: 154).

Esta inferiorización moral da lugar a un dolor, a unos sentimientos de injusticia en los que es posible apreciar los elementos que conforman un reclamo de merecimiento (persona merecedora, aquello que se reclama como merecido, la base sobre la que se reclama el merecimiento). Este reclamo conforma una 
voluntad de reivindicación que conduce en unos casos a acciones formales para obtener lo que se considera justo y merecido. Así lo expresa Núria, madre de Maria:

“Tenía muy claro que llegaría hasta el final, yo quería que María lo recupere [el derecho de sufragio], o sea... claro, porque María mira a los políticos, y yo qué sé, ayer decía, por ejemplo, cuando Duran i Lleida ${ }^{24}$ no fue electo, 'mira, no ha salido para el gobierno, ja ja ja', o yo qué sé... iCaray! iElla se lo merece, ella disfruta y de las cosas que disfruta déjala disfrutar! ¿no? Yo tenía muy claro que quería llegar hasta el final [...] es que tenía muy claro que llegaría donde sea para que la María recupere el derecho a votar, que removería cielo y tierra, lo tenía clarísimo" [Núria, comunicación personal].

En otros casos, si bien no se opta por acciones formales, la voluntad de reivindicación lleva a la elaboración de profundas críticas sobre la autoridad para juzgar debido al escaso conocimiento que pueden tener los jueces sobre las personas cuya capacidad juzgan. Estos reclamos se basan en la diferencia entre el conocimiento vital que tienen sobre la persona sus familiares y el conocimiento burocrático que los operadores jurídicos pueden llegar a tener tras los pocos minutos de que disponen para el reconocimiento judicial y las pruebas médico-forenses. Este sentimiento de injusticia articula reclamos de merecimiento y de derecho en los que las dimensiones morales y jurídicas aparecen imbricadas. En palabras de Carolina, madre de Karla:

"¿Lo terrible del caso, sabes qué es? Mira, los padres podemos estar obcecados, pero si los padres pedimos una incapacitación parcial, encima van dos personas que son testigos, que son de la familia, claro, lógicamente que conocemos a Karla y que pedimos una incapacitación parcial, ¿̇con qué derecho un juez, después de hablar con mi hija cinco minutos y de haberle presentado unos papeles que además tampoco decían la realidad de Karla... ¿con qué derecho él nos dice que tenemos una total? Es que esto... es que es absurdo todo esto, o sea, es que la sensación es decir "pero oye, yo no te lo pedî’" [Carolina, comunicación personal].

Asimismo, la imbricación entre las dimensiones jurídicas y morales se puede apreciar en el uso de la noción de persona. ${ }^{25}$ Tal como se expresa en el lenguaje

24 Miembro y presidente del extinto partido político democristiano nacionalista catalán Unió Democrática de Catalunya, socio de la federación Convergència i Unió, la cual gobernó en Cataluña entre el 2010 y el 2016 y aplicó duras políticas de austeridad (las llamadas retallades) en los ámbitos de salud, vivienda, educación, servicios sociales, agricultura, entre otros.

25 Para ampliar al respecto, ver el trabajo seminal de Mauss (1971 [1938]). 
del merecimiento, esta noción implica no solamente tener unos derechos y la posibilidad de ejercerlos, sino el reconocimiento de "ser persona" más allá de unas determinadas capacidades:

"Cuando tú conoces a Karla entiendes que puede no sumar, que se puede equivocar y decir que el rey es el Rajoy o no decir quién es el rey y ya no recuerdo si es que metió la pata o si se quedó en blanco y no supo quién era el rey... pero tú la conoces y dices ijolín, es que es una persona, caray, es que es una persona con todas las de la ley... y que tiene, que tiene que conservar todos sus derechos, con todas las protecciones, pero todos sus derechos!" [Carolina, comunicación personal].

Como esta expresión muestra, lo que está en juego es algo tan básico como el hecho de ser percibido como un miembro de la comunidad. Pero el hecho de que este reclamo subraye unos derechos de ciudadanía no debería hacernos perder de vista que no se trata solamente de un reclamo de derecho, sino también de merecimiento: un reclamo de pertenencia a una comunidad delimitada en este caso por unos determinados atributos de la persona que incluyen y van más allá de los aspectos jurídicos.

\section{¿EL FIN DE LAS INSTITUCIONES APARENTEMENTE BENIGNAS?}

Independientemente del tipo de respuesta, el análisis de los discursos elaborados en torno a la experiencia del proceso de incapacitación revela la utilidad de la noción de merecimiento para captar las concepciones de injusticia en las que se articulan elementos jurídicos y morales. En los casos en que los reclamos se expresaron mediante acciones formales, es destacable el hecho de haber apelado a instrumentos del derecho internacional para recurrir las resoluciones judiciales, es decir, a una codificación diferente a la utilizada para juzgar y sentenciar la incapacidad. Por otra parte, en los casos de reivindicación no formalizada, la percepción de injusticia e inmerecimiento no es menos intensa. Eventualmente, la ausencia de reivindicaciones formales se puede deber a muchos factores, entre los que cabe considerar los costes emocionales, económicos y temporales que puede implicar un nuevo proceso judicial.

Más allá de los supuestos legales que la configuran, la incapacitación implica un cierto juicio moral. Se trata de un juicio complejo: a la vez que busca proteger a la persona, parte de unos prejuicios que la ubican en una categoría estigmatizada, elaborada desde la perspectiva médico-rehabilitadora. La acción resultante de ello es un acto profundamente paternalista. El sesgo médico-rehabilitador inscrito en el ordenamiento jurídico español apunta a dejar patente la deficiencia, considerando solamente las carencias de la persona y no qué apoyos requeriría para complementar su capacidad. La preminencia 
de este sesgo señala una paradoja: para establecer una figura de protección, es necesario despojar a la persona de todo vestigio de aquello que se afirma que carece (sus capacidades). Ya que la incapacitación requiere de la constatación de la deficiencia permanente que afecte a la capacidad de autogobierno, se da una especie de deficientización obligatoria, la cual consiste en la proyección de una representación devaluada de la persona (Rodríguez y Cano 2015: 68-69). Como su nombre indica, no se trata de la constatación de la ausencia de capacidades, sino de la negación de las que se posee y las que se puede poseer con los apoyos pertinentes. Esto refuerza el sentimiento de injusticia debido a ser tratado como inferior, así como al fallo en la corrección de una representación errónea.

Los sentimientos de injusticia que surgen en torno a la incapacitación judicial muestran que las clasificaciones realizadas de acuerdo con el mérito personal (ser considerado incapaz, carente de autonomía, inhábil) ${ }^{26}$ crean estatus legales y refuerzan estereotipos. La conformación de dichos estatus legales se muestra como necesaria para establecer unas medidas de protección legal. Pero junto con estas medidas, se solidifica una representación errónea, un mal-reconocimiento.

El lenguaje del merecimiento permite visibilizar una ideología médico-rehabilitadora actuando detrás de las situaciones que son percibidas como injustas. Los reclamos que emergen en los relatos del proceso de incapacitación se refieren a merecer otro trato, otra consideración, que se tengan en cuenta unos aspectos y otros no, que se pondere más la vida cotidiana de la persona (la dimensión pragmática, lo que la persona realmente hace, siente, piensa) que la representación que se tiene de ella (la dimensión semántica que opera en el ordenamiento y eventualmente el prejuicio que se tiene sobre la discapacidad). Estos reclamos apuntan a no merecer ser tratado bajo un estereotipo y a no merecer medidas que, como la negación del derecho de sufragio, en poco o nada resuelven las necesidades de protección.

La incapacitación es una institución aparentemente benigna basada en prejuicios y estereotipos (Fiala-Butora y Stein 2016: 205). Es llamativo que apunte a la protección de la persona actuando sobre ella, pero no sobre las fuentes de los posibles daños de los cuales se la pretende proteger. Esto se debe al hecho de tener implícito un sesgo médico-rehabilitador, el cual se traduce en este contexto en una actuación individualizadora. Esta manera de proteger puede parecer muy efectiva; sin embargo, al partir de una lógica sustitutoria, los derechos, voluntad y preferencias de la persona no son tenidas en cuenta.

26 Cabe tomar nota de que no existe equivalencia entre las nociones de "capacidad jurídica" y la capacidad (mental, intelectual, memorística) que se intenta comprobar en los procesos de incapacitación judicial: la primera es una noción jurídica, mientras que la segunda es el resultado de una prueba medicalizada. 
Eventualmente, las medidas de protección que puede ofrecer sólo resuelven parcialmente las situaciones que llevan a las familias a buscar algún tipo de protección para sus hijos e hijas. Como hemos visto, en algunos casos este tipo de protección supone la privación del derecho de sufragio, poniendo en entredicho los anhelos de inclusión.

Como ha señalado Marta Nussbaum (2009: 336), la privación del derecho de sufragio pone a las personas a las que les es negado en una posición de subordinación e indignidad en comparación a las demás, denotando un fallo en el reconocimiento de su igual dignidad. La recepción negativa de la inhabilitación del derecho de sufragio es concebida como una injusticia por cuanto implica la imposibilidad de participar en la vida política de la comunidad. Empero, como un abogado de los casos tratados me comentó, "el derecho a votar es percibido como un derecho menor". En una sociedad que se define formalmente como democrática, esto es cuando menos algo paradójico.

Recientemente, la legislación electoral ha sido modificada en lo concerniente a la privación del derecho de sufragio de las personas incapacitadas, con el afán de extender el derecho de sufragio a todas las personas con discapacidad (Ley Orgánica 2/2018). ${ }^{27}$ La modificación ha llegado tras varios años de reivindicaciones por vías formales e informales, entre las que hay que considerar desde los recursos de apelación realizados por familias inconformes con los fallos de las sentencias de incapacitación, ${ }^{28}$ la presión realizada por parte del movimiento asociativo del sector de la discapacidad, hasta las observaciones planteadas por el Comité sobre los Derechos de las Personas con Discapacidad

27 Ley Orgánica 2/2018, de 5 de diciembre, para la modificación de la Ley Orgánica 5/1985, de 19 de junio, del Régimen Electoral General para garantizar el derecho de sufragio de todas las personas con discapacidad", en Boletín Oficial del Estado, 294, de 6/12/2018, disponible en < https://www.boe.es/ diario_boe/txt.php?id=BOE-A-2018-16672 > (última consulta en febrero de 2020).

28 Por su recorrido jurisdiccional, es destacable el caso de Mara, una joven gallega que fue privada del derecho a sufragio en el proceso de incapacitación judicial. La inconformidad con la sentencia llevó a sus padres a recurrir la decisión en la Audiencia Provincial, en el Tribunal Supremo e incluso en el Tribunal Constitucional. En todas estas instancias se ratificó la privación del derecho de sufragio. Solamente en el último tribunal se emitió un voto particular en el cual una de las magistradas animaba a los padres a seguir luchando para que se reconociera el derecho a su hija. Cf. "Sentencia Audiencia Provincial 781/2015, de 11 de marzo", Consejo General del Poder Judicial, Santiago de Compostela, ECLI: ES:APC:2015:781, disponible en < http://www.poderjudicial.es/search/doAction?action=contentpdf\&databasematch $=$ AN\&reference $=7357407 \&$ links $=\&$ optimize $=20150424 \&$ publicinterface $=$ true $>$ (última consulta en febrero de 2020); "Sentencia Tribunal Supremo 1163/2016, de 17 de marzo", Consejo General del Poder Judicial, Sala de lo Civil, Madrid, ECLI: ES:TS:2016:1163, disponible en $<$ http://www.poderjudicial.es/search/doAction?action=contentpdf\&databasematch=TS\&referen$c e=7628743 \&$ links $=$ nueva $\% 20$ york $\&$ optimize $=20160329 \&$ publicinterface $=$ true $>$ (última consulta en febrero de 2020); y "Auto 196/2016, de 28 de noviembre", Tribunal Constitucional de España, Sección Tercera, ECLI: ES:TC:2016:196A, disponible en < http://hj.tribunalconstitucional.es/HJ/es/Resoluc ion/Show/25214\#complete_resolucion > (última consulta en febrero de 2020). 
(CRPD 201 1: 5-6). Estas reivindicaciones han llevado también a que se planteen modificaciones en la legislación civil para poner fin a la práctica de la incapacitación judicial. ${ }^{29}$ Queda por ver si estas reformas legales supondrán un verdadero fin a las fuentes de injusticia (legales, pero además morales) o si, por el contrario, la presunción de incompetencia que determina quién merece o no ciertos derechos se desplazará a otros ámbitos, (re)produciendo situaciones de injusticia.

\section{BIBLIOGRAFÍA}

ABBERLEY, Paul, 1987, “The concept of oppression and the development of a social theory of disability", Disability, Handicap \& Society, 2 (1): 5-19, disponible en < https://disabili ty-studies.leeds.ac.uk/wp-content/uploads/sites/40/library/Abberley-chapter10.pdf > (última consulta en febrero de 2020).

ALVAREZ-URÍA, Fernando, 1983, Miserables y Locos: Medicina Mental y Orden Social en la España del Siglo XIX. Barcelona, Tusquets.

BARRANCO, María del Carmen, Patricia CUENCA, y Miguel Ángel RAMIRO, 2012, "Capacidad jurídica y discapacidad: el artículo 12 de la Convención de derechos de las personas con discapacidad", Anuario Facultad de Derecho, 5: 53-80, disponible en < http://sid.usal. es/idocs/F8/ART21552/barranco.pdf > (última consulta en febrero de 2020).

CHAUVIN, Sébastien, Blanca GARCÉS-MASCAREÑAS, y Albert KRALER, 2013, "Employment and migrant deservingness", International Migration, 51 (6): 80-85, disponible en $<$ https://doi.org/10.1111/imig.12123> (última consulta en febrero de 2020).

CHAUVIN, Sébastien, y Blanca GARCÉS-MASCAREÑAS, 2014, "Becoming less illegal: deservingness frames and undocumented migrant incorporation", Sociology Compass, 8 (4): 422-432, disponible en < https://doi.org/10.1111/soc4.12145> (última consulta en febrero de 2020).

CRPD - Comité sobre los Derechos de las Personas con Discapacidad, 2011 , "Examen de los informes presentados por los Estados parte en virtud del artículo 35 de la Convención. Observaciones finales. España (CRPD/C/ESP/CO/1)", Naciones Unidas, Comité sobre los Derechos de las Personas con Discapacidad, disponible en < https://tbinternet.ohchr. org/_layouts/treatybodyexternal/Download.aspx?symbolno=CRPD $\% 2 \mathrm{fC} \% 2 \mathrm{fESP} \% 2 \mathrm{f}-$ CO\%2fl\&Lang=en > (última consulta en febrero de 2020).

CRPD - Comité sobre los Derechos de las Personas con Discapacidad, 2014, “Observación general n. ${ }^{\circ} 1$ (2014): artículo 12: igual reconocimiento como persona ante la ley (CRPD/C/

29 El Anteproyecto de Ley por la que se reforma la legislación civil y procesal en materia de discapacidad fue elaborado en septiembre de 2018 tras una consulta pública realizada unos meses antes. Más de un año después de su aprobación para tramitación parlamentaria, el anteproyecto continúa en pausa. 
GC/1)", Naciones Unidas, Comité sobre los Derechos de las Personas con Discapacidad, disponible en < https://documents-dds-ny.un.org/doc/UNDOC/GEN/G14/031/23/PDF/ G1403123.pdf?OpenElement > (última consulta en febrero de 2020).

ENDARA ROSALES, Juan, 2018, "Discapacitat intel-lectual en el context jurídic: etnografia (més enllà) dels processos d'incapacitació judicial”, en Juan Endara Rosales, Nuria Sala Pardo y Cristina Arroyo Martín, Aprehendre la Diferència: Processos de Discapacitació a la Barcelona Contemporània. Barcelona, Pol·len - Institut Català d'Antropologia, 143-217.

FELDMAN, Fred, and Brad SKOW, 2016, "Desert", en Edward N. Zalta (coord.), The Stanford Encyclopedia of Philosophy (Winter 2016 Edition), disponible en < https://plato.stanfor d.edu/archives/win2016/entries/desert/ > (última consulta en febrero de 2020).

FERNÁNDEZ DE BUJÁN, Antonio, 201 1, "Capacidad. Discapacidad. Incapacitación: modificación judicial de la capacidad”, Revista Jurídica de la Universidad Autónoma de Madrid, 23 (1): 53-81, disponible en < https://revistas.uam.es/revistajuridica/article/view/5992 > (última consulta en febrero de 2020).

FIALA-BUTORA, Janos, y Michael A. STEIN, 2016, "The law as a source of stigma or empowerment: legal capacity and persons with intellectual disabilities", en K. Scior y S. Werner (coords.), Intellectual Disability and Stigma: Stepping Out from the Margins. Londres, Palgrave Macmillan, 195-207.

FRASER, Nancy, 2000, “¿De la redistribución al reconocimiento? Dilemas de la justicia en la era 'postsocialista' ”, New Left Review, 0: 126-155.

HOWE, Leo, 1990, Being Unemployed in Northern Ireland: An Ethnographic Study. Cambridge, Cambridge University Press.

KATZ, Michael B., 1989, The Undeserving Poor: From the War on Poverty to the War on Welfare. Nueva York, Pantheon Books.

MAUSS, Marcel, 1971 [1938], "Sobre una categoría del espíritu humano: la noción de persona y la noción del 'yo' ”, en M. Mauss, Sociología y Antropología, Madrid, Tecnos, 307-333.

NUSSBAUM, Martha, 2009, “The capabilities of people with cognitive disabilities", Metaphilosophy, 40 (3-4): 331-351, disponible en < https://doi.org/10.1111/j.1467-9973.200 9.01606.x > (última consulta en febrero de 2020).

ONU - Organización de las Naciones Unidas, 2006, Convención sobre los Derechos de las Personas con Discapacidad, disponible en <www.un.org/esa/socdev/enable/documents/tcccon vs.pdf $>$ (última consulta en febrero de 2020).

PAlacios, Agustina, 2008, El Modelo Social de la Discapacidad: Orígenes, Caracterización y Plasmación en la Convención Internacional sobre los Derechos de las Personas con Discapacidad. Madrid, Cinca.

PÉREZ DE HERRERA, Cristóbal, 1598 [1558], Discurso de Amparo de los Legítimos Pobres y Reducción de los Fingidos, Madrid, Luis Sánchez, disponible en < http://www.cervantesvirt ual.com/nd/ark:/59851/bmczg6k3 > (última consulta en febrero de 2020).

PICATOSTE BOBILlO, Julio, 2006, "La incapacitación: el marco jurídico", Revista Gallega de Psiquiatría y Neurociencias, 8: 34-79, disponible en < https://dialnet.unirioja.es/descarga/ articulo/5157928.pdf > (última consulta en febrero de 2020).

PUTNAM, Daniel, et al., 2019, "Disability and justice”, en Edward N. Zalta (coord.), The Stanford Encyclopedia of Philosophy (Fall 2019 Edition), disponible en $<$ https://plato.stanf ord.edu/archives/fall2019/entries/disability-justice/ > (última consulta en febrero de 2020). 
RODRÍGUEZ, Susana, y Amparo CANO (coords.), 2015, Discapacidad y Políticas Públicas: La Experiencia Real de los Jóvenes con Discapacidad en España. Madrid, Catarata.

SIMPLICAN, Stacy, 2015, The Capacity Contract: Intellectual Disability and the Question of Citizenship. Minneapolis, University of Minnesota Press.

TOBOSO, Mario, y Francisco GUZMÁN, 2009, "Diversidad funcional: hacia la deconstrucción del cuerpo funcionalmente normativo", presentado en el I Congreso Internacional de Cultura y Género: La Cultura en el Cuerpo, Universidad Miguel Hernández, 11 -13 de noviembre, disponible en < https://digital.csic.es/bitstream/10261/23424/1/MarioTo boso-FranciscoGuzman_I-Congreso-SIEG-2009.pdf > (última consulta en febrero de 2020).

UPIAS - Union of the Phisically Impaired Against Segregation, 1976, "Fundamental principles of disability", en < https://disability-studies.leeds.ac.uk/wp-content/uploads/sites/4 0/library/UPIAS-fundamental-principles.pdf > (última consulta en febrero de 2020).

VIVES, Juan Luís, 2004 [1526], De Subventione Pauperum (Sobre el Socorro de los Pobres). Valencia, Delegación de Cultura, disponible en < http://bivaldi.gva.es/il 8n/corpus/unida d.cmd ?idCorpus $=1$ \&idUnidad $=11629$ \&posicion $=1>$ (última consulta en febrero de 2020).

WALEN, Alec, 2016, "Retributive justice", en Edward N. Zalta (coord.), The Stanford Encyclopedia of Philosophy (Winter 2016 Edition), disponible en < https://plato.stanford.edu/archi ves/win2016/entries/justice-retributive/ > (última consulta en febrero de 2020).

YOUNG, Iris Marion, 1997, “Unruly categories: a critique of Nancy Fraser's dual systems theory", New Left Review, I (222): 147-160.

YOUNG, Iris Marion, 2000, La Justicia y la Política de la Diferencia. Madrid, Ediciones Cátedra. 